\title{
The Prospect of 5G Technology Applied to Distance Medical Education and Clinical Practice
}

\author{
Jiaqi Xu1 ${ }^{*}$, Yujie Cui ${ }^{2 *}$, Xinfeng Huang1, Shifu Mo1, Liangyue Wang ${ }^{1}$, Guangjin Su1, Yong Cheng1\# \\ ${ }^{1}$ Burn and Plastic Surgery, The Fifth Affiliated Hospital, Sun Yat-sen University, Guangzhou, China \\ ${ }^{2}$ Rheumatology, The Fifth Affiliated Hospital, Sun Yat-sen University, Guangzhou, China \\ Email: "412359823@qq.com, "drcare@protonmail.com
}

How to cite this paper: Xu, J. Q., Cui, Y. J., Huang, X. F., Mo, S. F., Wang, L. Y., Su, G. J., \& Cheng, Y. (2020). The Prospect of 5G Technology Applied to Distance Medical Education and Clinical Practice. Creative Education, 11, 2837-2845.

https://doi.org/10.4236/ce.2020.1112209

Received: November 4, 2020

Accepted: December 21, 2020

Published: December 24, 2020

Copyright $\odot 2020$ by author(s) and Scientific Research Publishing Inc. This work is licensed under the Creative Commons Attribution International License (CC BY 4.0).

http://creativecommons.org/licenses/by/4.0/

\begin{abstract}
The combination of network communication and medical education gave birth to distance medical education (DME). Now the fifth generation of mobile communication technology (5G) with high data rate, low delay, save energy, reduce cost and other advantages to the telemedicine education has provided a substantial change. It can make the utilization of excellent resources have sufficiency and high efficiency, which equalize educational resources. Teachers can stay face-to-face with students, even if they are in different places. It makes the teaching content is updated in time and so on. This paper reviews the development history of distance medicine education and looks forward to the prospect brought by the combination of $5 \mathrm{G}$ communication technology. How to guide clinical practice and improve the learning efficiency and interest.
\end{abstract}

\section{Keywords}

5th Generation Mobile Networks, Medical Education, Network Information Society, Medical Students, Clinical Practice

\section{Introduction}

Technological innovation has not only impacted social change in recent years but has been the prime driver of educational transformation (Garrison, 2011). The electronic information and networks promotes the development of medicine and medical education. The traditional experiential medical education develops to the evidence-based medical education and pursues seeking truth from *First author. 
facts, and the medical environment is becoming more and more complex, it requires medical educators to constantly improve the efficiency and quality of knowledge updating. However, difficulties exist in some health professionals' access to ongoing professional development opportunities, particularly those with limited access face-to-face education (Lenthall, 2011; Bennett, 2014), due to geographical isolation or for those not enrolled in a formal program of study (Doorenbos, 2011; Curran, 2006). These issues challenge traditional methods of teaching delivery; electronic learning is at the nexus of overcoming these challenges (Gilligan et al., 2015). The network development determines the efficiency of electronic learning. With the development and popularization of the latest $5 \mathrm{G}$ mobile communication technology, it has the advantages of high speed transmission rate and low delay (Costanzo, 2017). It will made huge revolution to the mobile communication and telemedicine education.

\section{DME in Past}

The development of distance education in our country has gone through three generations since the 1970s. The first generation is correspondence education with paper printing as the carrier. In the 1980s, the second generation of radio and television education emerged in the form of the transmission of sound and images via electronic means. The third generation is the 1990s, with the development of information and network technology, computer and network multimedia technology as the support of the modern distance education system (Jing, 2009; Meng, 2009).

Online tertiary and professional education is not new (Newman, 2004; Mugisha, 2009; Li, 2004). But, DME resources are insufficient, obsolete, slow to update and less innovative. Teaching resources are the core of DME, it also affects the degree of recognition and teaching effect of DME. The current medical students generally report that the teaching video content is relatively old, slow to update, less innovative, more imitative, and the remote teaching equipment is bulky and poor mobility. The root cause of this problem is that educational content and network technology have not formed a true optimal combination.

Teachers' knowledge needs to be updated in time, which can improve teaching quality and benefit interns in clinical practice. Given the increasing complexity and pressures of healthcare delivery, new approaches to teaching and learning, and competing demands on teachers' time, faculty members require a broad range of teaching and learning strategies that can be used in diverse settings (Gilligan et al., 2015). In the past, partly due to the limited network speed, the professional knowledge of teachers cannot be updated timely.

\subsection{Shortage of Teachers}

In 1998, the Chinese Government announced a national policy to merge many of the free-standing health professional institutions into universities (Jiang, 1998; Hou, 2014). As the Figure 1 shows, the reform goal might have been to 


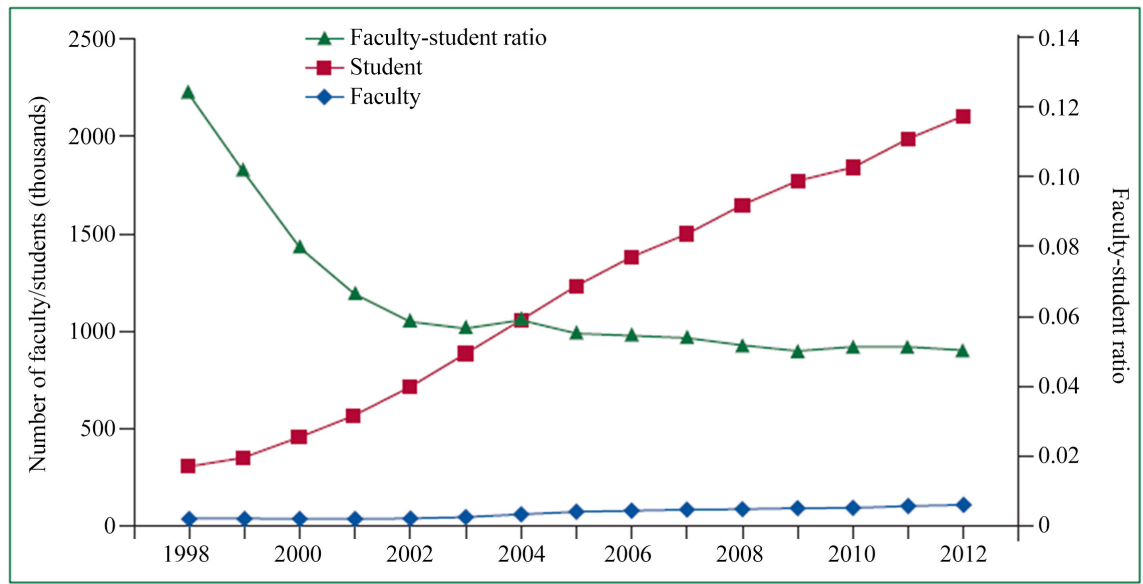

Figure 1. It shows the consequent trends of students, faculty members, and faculty-student ratios from 1998 to 2012 (Branagan, 2012).

modernise education along the developed country model, but the infrastructure, public funding, and especially the faculty might not have kept up with the expansion of student enrolment (Branagan, 2012). There is a serious shortage of teachers in medical undergraduate education in China, especially about to enter the stage of clinical practice. Each student gets less learning and hands-on opportunities, can not achieve the corresponding learning effect, the quality of teaching decline, leading to the reduction of students learning enthusiasm.

\subsection{Lacking of Face to Face}

In the current distance education, teachers can only provide students with simple learning support services such as relevant teaching information, course content, online and information-based homework submission and exams. Lack of interpersonal communication and media-based face to face communication with each other. Therefore, it is difficult for teachers to accurately understand the actual learning situation of students and fail to give timely and accurate guidance and help to the problems of students in the learning process. At the same time, without the guidance of teachers, it is difficult for students to cultivate and develop the ability of independent learning and better choose information resources for independent learning.

\subsection{Classes Will Be Suspended for Natural Disasters}

When natural disasters come, such as floods, snow, fires and outbreaks of infectious diseases, classes are often suspended, especially respiratory infections. The longer a natural disaster lasts, the greater the impact on medical education.

The disadvantages of distance education in China are as follows: lack of systematic theory, insufficient theoretical research, limited educational resources, single educational mode, unbalanced development of distance education, imperfect equipment and limited teacher skills. The tele-information transfer technologies commonly used in telemedicine include mobile communication, satellite, 
wireless network and so on (Feng, 2010). Satellite communication is characterized by transmission delay, easy interference and high cost. Wireless network has regional limitations, unstable transmission speed, large equipment and other disadvantages. If you have a light hardware, a software that supports live streaming, and a fast enough mobile network, all these problems will be easy to solve. $5 \mathrm{G}$ and concomitant emerging technologies can expect to be able to overcome these challenges. Compared with the above two communication methods, mobile communication, $5 \mathrm{G}$ is a representative, has more advantages. The advantages is light equipment, complete functions, high transmission speed, stable signal and so on.

\section{5G Communication}

Distance medical education relies on the scalability, transparency, fault tolerance, geographical coverage and security of mobile communication, it realize the ideal model of distance medicine education.

The $5 \mathrm{G}$ refers to the fifth generation of wireless transmission technology, which will bring great influence and change to every field of contemporary society, also includes medical education. Although the $5 \mathrm{G}$ technology is driven by a bundle of characters, such as data transfer rate, latency, coverage, power, and network energy usage, however, the following unique features are most valued to healthcare: 1) high-speed data transfer rate; 2 ) super-low latency (delay in the data transmission-response system); 3) the connectivity and capacity; 4) high bandwidth and durability per unit area (Li, 2019; Riva \& Gamberini, 2000), as Figure 2 shows.

Some scholars believe that the $5 \mathrm{G}$ era will be the fourth industrial revolution (Steinert, 2006). It is not only a new generation of mobile information technology, a symbol of scientific and technological progress, but also an organic combination of the era of artificial intelligence, the Internet of Things, the blockchain and the smart economy (Panwar, 2016).

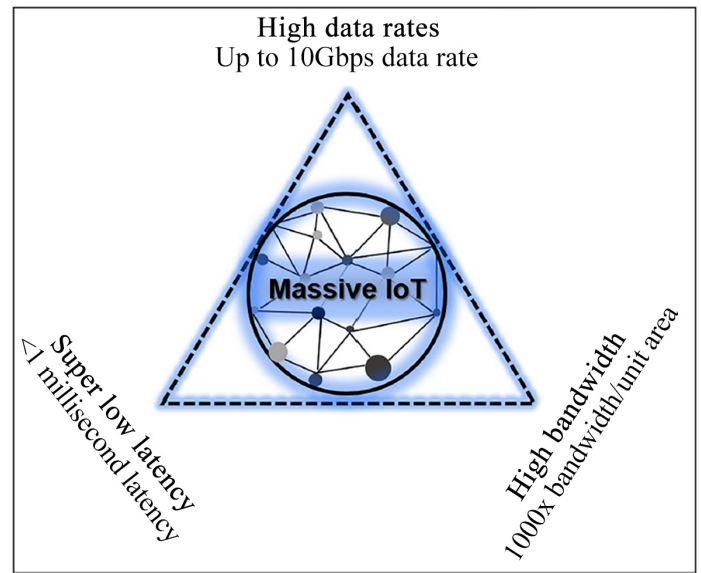

Figure 2. The basic features of $5 \mathrm{G}$ technology (Riva \& Gamberini, 2000). 
5G can bring huge economic benefits to the society, because 5G features high speed, low delay, high reliability and great connectivity, which can accelerate the development of new technologies, thus transforming traditional industries and creating new opportunities for the development of digital transformation in all walks of life. For example, THE integration of $5 \mathrm{G}$ with $8 \mathrm{~K}, \mathrm{AR} / \mathrm{VR}$ and other technologies, it also can promote the development of applications such as UHD live streaming, 3D video, cloud games and telemedicine education (Pattichis, 2002).

\section{Prospect}

\subsection{G in the Distance Medical Education}

The network information society develops rapidly. How can medical students learn more efficiently, more excellent, more able to adapt to the social, which poses great challenges to the traditional medical education. 5th generation mobile networks (5G) is a good bridge linking the network information society and medical education (Ullah, 2019). The performance goals of 5G are high data rates, low latency, energy savings, reduced costs, increased system capacity and large-scale device connectivity. Network information technology has been widely used in medical field, especially in the education of basic medical knowledge and clinical skills training, application of information technology can get rid of the limitation of traditional teaching, not only can the innovation teaching idea, expand teaching space, improve the teaching quality, still can improve teaching efficiency, reduce material inputs, thus effectively promote the teaching reform and development. With the $5 \mathrm{G}$, teachers can more easily talk with students face to face, impart theoretical knowledge and practical experience, conduct interaction and discussion, guide simple operational exercises, and conduct examinations and tests, even if they are thousands of miles apart. Although 5G technology is still in the initial stage of development, its unique advantages determine its broad application prospects in medical education.

Due to the rapid development of 5G technology in China, commercial 5G technology has been gradually applied in some fields, and the medical field has been explored in combination with the advantages of $5 \mathrm{G}$ technology. At present, domestic and foreign $5 \mathrm{G}$ technologies are mainly applied in the medical fields of remote consultation, remote monitoring, remote surgery, remote teaching, intelligent guidance, mobile medical care, artificial intelligence assisted diagnosis and treatment, etc. (Ullah, 2019; Fitts, 1967). At present, mobile communication devices and technologies are rapidly updated. Mobile communication devices, typical representatives of which are mobile phones and tablets, can be combined the advantages of $5 \mathrm{G}$ with APP software which have the live broadcast function, traditional medical education mode can be broken and new medical distance education mode can be explored. Solve the problems existing in traditional medical education. 


\subsection{Application of 5G in Clinical Practice}

At present, most medical students in internship generally report that most medical schools are short of substitute teachers, uneven distribution of quality teaching resources or insufficient, etc. For example, a teacher takes more than one or even more than a dozen students, so the room in the ward and the sight of teaching is limited. The number of patients and typical diseases encountered by the teachers in the remote and underdeveloped areas is small and the equipment is limited. In areas where teachers are insufficient, students can sit in the classroom and open the studio set up by the teacher with their mobile phones. The teacher only needs to hold the mobile phone while making ward rounds and broadcast live. The perspective is more comprehensive and intuitive, so as to reduce overcrowding in the ward and avoid affecting the ward environment. If patients and diseases in remote and underdeveloped areas are limited and the equipment is backward, they can cooperate with medical colleges and affiliated hospitals in coastal areas and other medical developed areas to hire highly educated and experienced professors to teach, and even if they are far away from home, they can teach on-site. This can be achieved only with a mobile phone and a 5G network. In this way, students can learn more kinds of diseases and learn more advanced medical equipment even in remote areas.

Students will encounter many clinical problems in clinical practice. In the past, they had to go to the library or surf the Internet to find relevant books after work to solve problems. If they had $5 \mathrm{G}$ network speed and mobile phones and software supporting the network, they would immediately consult relevant literatures to solve problems. Obviously improve students' learning efficiency and sense of achievement, improve learning enthusiasm, and improve the quality of education.

Most of the surgical interns lack the relevant training to enter the operating room and work as an assistant on the operating table, or some hospitals have limited training but are relatively abstract, so they are not familiar with the relevant operation and are prone to make mistakes. Cognition is the first stage of learning complex procedures, as described by the Fitts-Posner 3-stage theory of motor-skill acquisition [24]. If the teacher can demonstrate the relevant operation of the operating room in the way of live broadcast by mobile phone, it will be more intuitive and easier for students to master and avoid mistakes.

Specific conditions, such as COVID-19 and other outbreaks of respiratory transmission. Medical education in areas with outbreaks of infectious diseases can impart knowledge and skills through the distance education system with little or no influence; greatly reduce the chance of transmission by contact. Online education is essential to achieving this aim and educators, course administrators and course designers all have a responsibility to deliver it effectively (Seymour-Walsh, 2020).

The next prospective experiment for evaluating of application of $5 \mathrm{G}$ in clinical Practice outcomes can use the Kirkpatrick's model, as the Figure 3 shows (Kirkpatrick, 1994; Steinert, 2006). 


\begin{tabular}{|l|l|l|}
\hline Level 1 & REACTION & $\begin{array}{l}\text { Participants' views on the learning experience, its organization, } \\
\text { presentation, content, teaching methods, and quality of instruction }\end{array}$ \\
\hline Level 2A & $\begin{array}{l}\text { LEARNING-Change } \\
\text { in attitudes }\end{array}$ & $\begin{array}{l}\text { Changes in the attitudes or perceptions among participant groups } \\
\text { towards teaching and learning }\end{array}$ \\
\hline Level 2B & $\begin{array}{l}\text { LARNING- } \\
\text { Modification of } \\
\text { knowledge or skills }\end{array}$ & $\begin{array}{l}\text { For knowledge, this relates to the acquisition of concepts, procedures } \\
\text { and principles; for skills, this relates to the acquisition of } \\
\text { thinking/problem-solving, psychomotor and social skills }\end{array}$ \\
\hline Level 3 & $\begin{array}{l}\text { BEHAVIOR-Change } \\
\text { in behaviors }\end{array}$ & $\begin{array}{l}\text { Documents the transfer of learning to the workplace or willingness of } \\
\text { learners to apply new knowledge \& skills }\end{array}$ \\
\hline Level 4A & $\begin{array}{l}\text { RESULTS-Change in } \\
\text { the system/ } \\
\text { organization practice }\end{array}$ & $\begin{array}{l}\text { Refers to wider changes in the organization, attributable to the } \\
\text { educational program }\end{array}$ \\
\hline Lever 4B & $\begin{array}{l}\text { RESULTS - Change } \\
\text { among the participants } \\
\text { students, residents or } \\
\text { colleagues }\end{array}$ & $\begin{array}{l}\text { Refers to improvement in student or resident learning/performance as a } \\
\text { direct result of the educational intervention }\end{array}$ \\
\hline
\end{tabular}

Figure 3. Kirkpatrick's model for evaluating educational outcomes (Steinert, 2006).

The prospect is worth expecting. With its fast transmission, low latency and high capacity technology, $5 \mathrm{G}$ is poised to lead and change the medical education. It will make significance for promoting the rapid development of DME, which making full use of advanced 5G advantages to improve the hardware and software facilities of DME, and also the efficiency of knowledge imparting and knowledge receiving. But more experiments are needed to verify this.

\section{Conflicts of Interest}

The authors declare no conflicts of interest regarding the publication of this paper.

\section{References}

Bennett, P. N. (2014). Increasing Home Dialysis Knowledge through a Web-Based e-Learning Program. Nephrology, 19, 345-351. https://doi.org/10.1111/nep.12231

Branagan, L. (2012). Organizational Implementation of Telemedicine Technology: Methodology and Field Experience. In Global Humanitarian Technology Conference (pp. 271-276). New York: IEEE. https://doi.org/10.1109/GHTC.2012.44

Costanzo, A. (2017). Energizing 5G: Near and Far Field Wireless Energy and Data Transfer as an Enabling Technology for the 5G IoT. IEEE Microwave Magazine, 18, 125-136. https://doi.org/10.1109/MMM.2017.2664001

Curran, V. R. (2006). Factors Influencing Rural Health Care Professionals' Access to Continuing Professional Education. Australian Journal of Rural Health, 14, 51-55. https://doi.org/10.1111/j.1440-1584.2006.00763.x

Doorenbos, A. Z. (2011). Enhancing Access to Cancer Education for Rural Healthcare Providers via Telehealth. Journal of Cancer Education, 26, 682-686.

https://doi.org/10.1007/s13187-011-0204-4 
Feng, S. (2010). Providing Telemedicine Services in an Infrastructure-Based Cognitive Radio Network. IEEE Wireless Communications, 17, 96-103. https://doi.org/10.1109/MWC.2010.5416356

Fitts, P. M. (1967). Human Performance. Oxford: Brooks/Cole.

Garrison, D. R. (2011). E-Learning in the 21st Century: A Framework for Research and Practice (2nd ed.). New York: Routledge.

Gilligan, P., Houlihan, A., \& Padki, A. (2015). The Doctor Will See You Now: A Study of Perspectives on Telemedicine in the Pre-Hospital Environment. Emergency Medicine Journal, 32, 989-990. https://doi.org/10.1136/emermed-2015-205372.29

Hou, J. (2014). Transformation of the Education of Health Professionals in China: Progress and Challenges. The Lancet, 384, 819-827. https://doi.org/10.1016/S0140-6736(14)61307-6

Jiang, Z. (1998). 985 Program. http://www.moe.gov.cn/publicfiles/business/htmlfiles/moe/s6183/201112/128828.html

Jing, H. Q. (2009). The Development of Distance Medical Education in China. Continuing Medical Education in China, 4, 11-14.

Kirkpatrick, D. L. (1994). Evaluating Training Programs: The Four Levels. San Francisco, CA: Berrett-Koehler Publishers.

Lenthall, S. (2011). Nursing Workforce in Very Remote Australia, Characteristics and Key Issues. Australian Journal of Rural Health, 19, 32-37. https://doi.org/10.1111/j.1440-1584.2010.01174.x

Li, D. (2019). 5G and Intelligence Medicine-How the Next Generation of Wireless Technology Will Reconstruct Healthcare? Precision Clinical Medicine, 2, 205-208. https://doi.org/10.1093/pcmedi/pbz020

Li, L. (2004). China's Higher Education Reform 1998-2003: A Summary. Asia Pacific Education Review, 5, 14-22. https://doi.org/10.1007/BF03026275

Mugisha, J. F. (2009). Using Information and Communication Technology to Revitalise Continuing Professional Development for Rural Health Professionals: Evidence from a Pilot Project. Rural and Remote Health, 9, 1222. http://www.rrh.org.au/journal/article/1222

Newman, C. (2004). Survey of a Video Conference Community of Professional Development for Rural and Urban Nurses. Rural and Remote Health, 9, 1134. http://www.rrh.org.au/journal/article/1134

Panwar, N. S. (2016). A Survey on 5G: The Next Generation of Mobile Communication. Physical Communication, 18, 64-84. https://doi.org/10.1016/j.phycom.2015.10.006

Pattichis, C. (2002). Wireless Telemedicine Systems: An Overview. IEEE Antennas and Propagation Magazine, 44, 143-153. https://doi.org/10.1109/MAP.2002.1003651

Riva, G., \& Gamberini, L. (2000). Virtual Reality in Telemedicine. Telemedicine Journal and e-Health, 6, 327-340. https://doi.org/10.1089/153056200750040183

Seymour-Walsh, A. E. (2020). Adapting to a New Reality: COVID-19 Coronavirus and Online Education in the Health Professions. Rural Remote Health, 20, 6000. https://doi.org/10.22605/RRH6000

Steinert, Y. (2006). A Systematic Review of Faculty Development Initiatives Designed to Improve Teaching Effectiveness in Medical Education: BEME Guide No. 8. Medical Teacher, 28, 497-526. https://doi.org/10.1080/01421590600902976

Ullah, H. (2019). 5G Communication: An Overview of Vehicle to Everything, Drones, and Healthcare Use Cases. IEEE Access, 7, 37251-37268.

https://doi.org/10.1109/ACCESS.2019.2905347 


\section{Abbreviations}

5G: Fifth-generation wireless network technology

DME: Distance medical education 